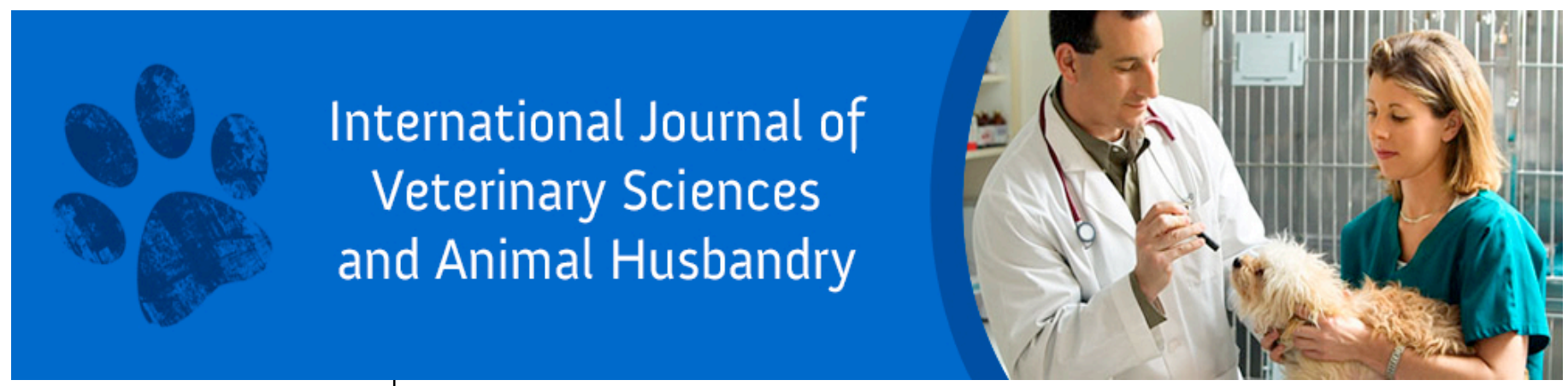

ISSN: $2456-2912$

VET 2020; 5(6): 39-45

(C) $2020 \mathrm{VET}$

www.veterinarypaper.com

Received: 11-09-2020

Accepted: 15-10-2020

Author Names and Affiliation Are Given Below

\section{Occurrence of brucellosis in pigs kept in confinement and free ranging systems in the Democratic Republic of the Congo}

\author{
Tshilenge Mbuyi Georges, Kazadi Kawaya E, Bha Nsekene G, Katshongo \\ Mushindua Freddy, Balowa Katshayi Louison, Tshinguta londji charlotte, \\ Dibungi Luseba Jean Marie, Kandu-lelo Clement, Lufulwabu Kasuyi \\ Jean, Mpiana Tshipamba Serge and Masumu Justin
}

DOI: https://doi.org/10.22271/veterinary.2020.v5.i6a.307

\begin{abstract}
Swine brucellosis is a zoonosis disease affecting pigs widely. It is caused by Brucella suis whose distribution is not well documented in various areas including the Democratic Republic of the Congo (DRC). This study was initiated to determine the extent of swine brucellosis in pigs kept in confinement or in divagation in peri-urban and rural areas of Kinshasa and Kongo Central provinces of the DRC. A total of 814 samples were collected in both provinces. ELISA and Rose Bengal Test (RBT) were performed to screen all the collected samples. A prevalence of $4.42 \%$ and $3.19 \%$ of cumulative IgG seroprevalence of $B$. suis was obtained in both provinces sampled using ELISA and RBT, respectively. At the province level, no difference was obtained in the seroprevalence obtained in Kinshasa and Kongo Central when ELISA (3.53\% and 5.38\%, RR: $\left.0.6570 \mathrm{p}=0.20 ; \chi_{2}=1.23\right)$ or RBT $(2.59 \%$ and $3.85 \%$, $\mathrm{p}=0.41 ; \chi 2=0.66)$ were used, respectively. Similarly, the seroprevalence obtained in animals aged between 7-12 months and those aged more than 12 months did not show any significant difference using ELISA $\left(3.53 \%\right.$ and $\left.5.54 \%, p=0.166 ; \chi^{2}=1.9167\right)$ or RBT $(3.09 \%$ and $3.32 \%, p=0.85 ; \chi 2=0,04)$, respectively. When animals reared in confinement or divagation systems were compared, no differences were also obtained using ELISA (6.76\% versus $3.62 \%, p=0.058 ; \chi 2=3.5980)$ or RBT $(3.86 \%$ and $2.97 \%$, $\left.\mathrm{p}=0.525 ; \chi^{2}=0.4038\right)$, respectively. However higher seroprevalence was recorded in males compared to females using ELISA (8.06\% versus $3.15 \%, p=0.0028 ; \chi 2=8.90)$ or RBT $(5.68 \%$ versus $2.32 \%$, $p=0.017$; $\chi^{2}=5.7256$ ), respectively. Similarly, when animals were compared based on their breeds, higher seroprevalences were recorded in indigenous pig breed compared to improved breed ones using ELISA (15.18\% and $\left.2.7 \%, \mathrm{p}=0.001 ; \chi^{2}=32.65\right)$ or RBT $\left(9.82 \%\right.$ and $\left.2.1 \%, \mathrm{p}=0.001 ; \chi^{2}=16,04\right)$, respectively. As far as it can be ascertained, this study reports the first investigation of swine brucellosis infecting indigenous and improved pig breeds in Kinshasa and Kongo Central provinces in the DRC. The presence of brucellosis antibodies in animals in these provinces highlights a high public health concern for this major zoonotic disease not well documented in health care structures in RDC.
\end{abstract}

Keywords: Brucellosis, Pigs, Free range, ELISA, RBT, Democratic Republic of the Congo

\section{Introduction}

Brucellosis is a notifiable zoonotic disease that affects livestock and wildlife around the world as well as human population ${ }^{[1]}$ with high socio-economic impact in livestock ${ }^{[2,3]}$. Brucella infections are widely distributed in domesticated animals especially in the developing countries ${ }^{[4]}$. This genus comprises several species among which Brucella abortus, $B$. melitensis, $B$. suis and $B$. canis that often cause abortion and infertility in these natural hosts ${ }^{[5]}$. Pigs are mainly infected by $B$. suis although they can also be infected with $B$. abortus or $B$. melitensis in areas where brucellosis is enzootic in ruminants ${ }^{[6]}$.

Pig infection with $B$. suis occurs by direct or indirect contact ${ }^{[7]}$. Infertility and abortion in sows and orchitis in boars ${ }^{[8]}$ are the main signs of the disease. Swine brucellosis can spread by venereal route and the boar is the main source either by direct contact during mating or via artificial insemination. This pathogen can infect some professions particularly those working in the slaughterhouses, famers and veterinarians ${ }^{[9]}$. 
Porcine brucellosis diagnosis can be performed by clinical signs observation i.e. arthritis, reproductive problems including; belated abortions, embryonic mortality, placental retentions, infertility, orchitises, epididymitides. Generally pigs affected by the disease may develop a number of these clinical signs, some remain clinically healthy, making laboratory testing an important diagnostic tool for disease confirmation. Currently the gold standard method for confirmation of Brucella infection is based on pathogen isolation in primary cultures that can take up to one week ${ }^{[10]}$ because of the low growth of this pathogen. Several other tools are available and have been widely used for survey of Brucella spp among which the standardized Rose Bengale Test (RBT) that is recommended by OIE as a screening test for its simplicity and the Fixation Complement Test (FCT) as a confirmatory test ${ }^{[11]}$. The fluorescence polarization assay (FPA), the Competitive-Enzyme Linked immunosorbant assay (C-ELISA) and the Indirect- Enzyme Linked immunosorbant assay (I-ELISA) are often used for massive screening ${ }^{[12,13]}$. The use of PCR allows the identification of $B$. suis and the discrimination of various species $[14,15,16,17]$. This technique helps in reducing the time required to obtain the results ${ }^{[18]}$ but it is only useful during the time when the pathogens circulate in the body.

Brucellosis can have multiple socio-economic consequences in infected pig farms. It causes direct losses on animal productivity (mortality, fertility decline, infertility...). Indirect losses are also encountered and are often related to the cost of treatment and prevention measures. Its zoonotic character and the fact that it is more often not well known by health care personal makes it a real Public Health threat especially in areas were the infection is prevalent in animals. To contain the spread of brucellosis, offensive methods based on elimination in infected farms and defensive ones that prevent the introduction of the pathogen or the spread of the disease in non-infected farms can be successfully used.

In the Democratic Republic of the Congo (DRC), pigs are mainly reared by the local community members with very limited resources either in a traditional or in a semi modern farming system. Those animals do not receive adequate veterinary care and are mainly exposed to diseases such as African swine fever or porcine cysticercosis that has considerable impact on production ${ }^{[19]}$. In most of these farms biosecurity measures are poorly respected and farmers are exposed to professional diseases which list is not currently determined. Although brucellosis is known to be present in sub-Saharan countries ${ }^{[20,21]}$ including DRC in cattle ${ }^{[22]}$, no survey has so far been conducted for the possible occurrence of $B$. suis in pigs despite cases of abortions and infertility that are commonly reported in pig industry. The current study was thus initiated to determine the presence of brucellosis in apparently healthy pigs reared in confinement and in divagation farms in Kinshasa and Kongo Central provinces.

\section{Materials and Methods \\ 2.1 Study area}

This study was carried out from 2010 to 2014 in Kinshasa and Kongo Central Provinces in DRC. Kinshasa is the capital and one of the 26 provinces of the DRC. It is located in the western part of the country and is about $300 \mathrm{~m}$ above the sea level. Kinshasa province is situated at Latitude $4^{\circ} 19$ ' $54^{\prime \prime S}$ and Longitude $15^{\circ} 18^{\prime} 50^{\prime \prime E}$ covering an area of 9,965 $\mathrm{km}^{2}$. Its hydrography is dominated by the Congo River on the western side which forms the large Pool Malebo separating the two most closed capitals (Kinshasa and Brazzaville, Republic of Congo) in the world. The province is characterized by a tropical climate with an average annual temperature oscillating around $25^{\circ} \mathrm{C}$ while the annual average precipitation ranges around $1,400 \mathrm{~mm}$ per year. Pig farming is highly developed in Kinshasa, especially in the hinterlands of the city. Most farmers use the confinement system whereby animals are kept in claustration day and night (intensive system). Some pig keepers use a typical or familial system, leaving animals in full liberty (traditional, extensive or divagation system). Semi-intensive system is also used in which animals are free during the day and kept in houses at night.

Kongo Central province is situated at Latitude $5^{\circ} 49^{\prime} \mathrm{S}$ and Longitude $13^{\circ} 29^{\prime} \mathrm{E}$ covering an area of $53,947 \mathrm{~km}^{2}$. Its economy lies mainly upon the agro-pastoral sector. The province is characterized by a tropical climate with dry season extending over 4 months (from May to September). The average annual temperature oscillates around $25^{\circ} \mathrm{C}$. Annual average rainfall ranges from $900 \mathrm{~mm}$ (extreme South West of the province) to $1,500 \mathrm{~mm}$ (extreme east of Province). Pig farming is mainly based on traditional type; the intensive and semi-intensive systems are mainly found in cities.

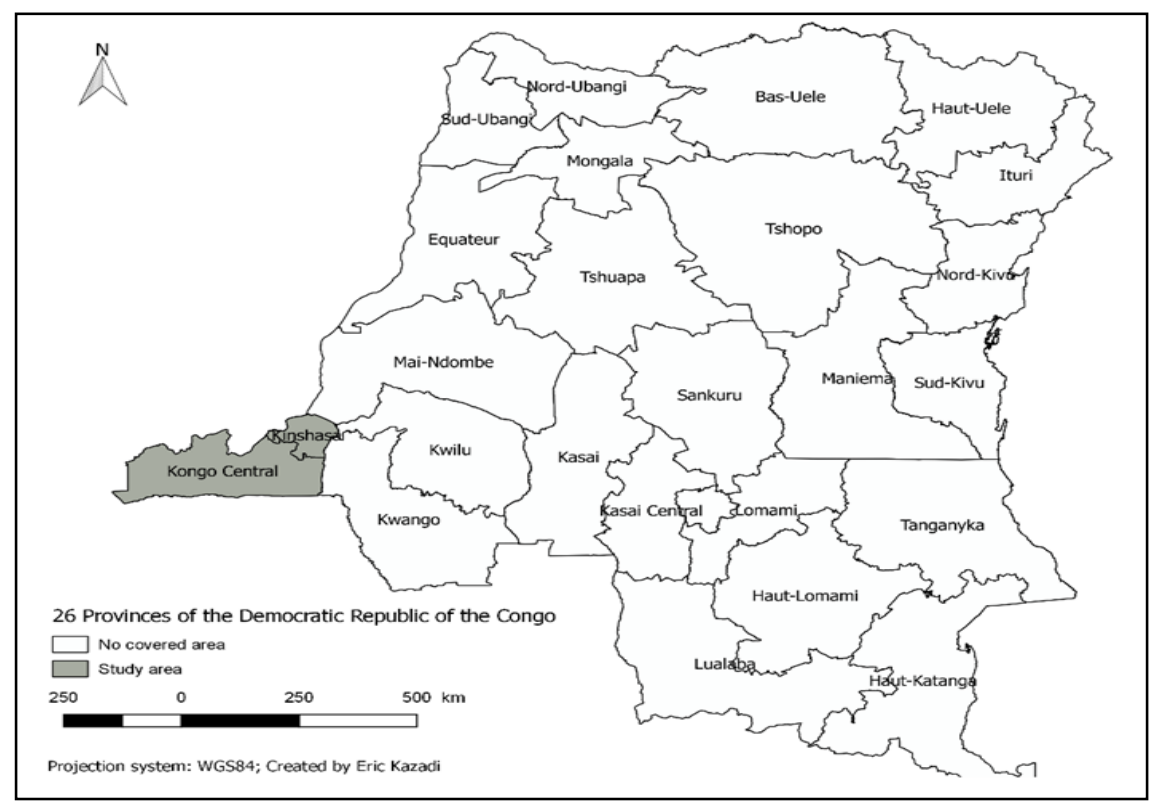

Fig 1: DRC Map showing the provinces where the study areas $\sim 40 \sim$ 


\subsection{Sample size determination \\ 2.3.1 Sample collection}

The sample size in each area was calculated considering an infinite population (no recent census data is available) using the formula adopted from researcher ${ }^{[23]}$ as follows: $n=Z^{2}$ $P(1-P) / d^{2}$, where $n$ is the required sample size; $Z$ is the multiplier from normal distribution (1.96); $\mathrm{P}$ is the estimated prevalence which is $50 \%$ considering the fact that there was no reliable prevalence data for brucellosis pigs in Kinshasa or Kongo Central province; (1-P) is the probability of having no disease and $d$ is the desired precision (5\%). The level of confidence for the study was set at 95\% confidence interval. Based on this formula, the total number of animals required was 384 pigs in each selected province. A total of 814 samples were collected for this study (Kinshasa: $n=424$ and Kongo Central: $n=390$ ).

Samples were randomly collected after the owner's farm consent has been obtained. In this study, piglets and pigs younger than $\leq 7$ months old (sow and boar's) and weak pigs which might be unfortunately affected by bleeding were excluded from the study. Data for each pig sampled (age, sex, origin of pig, sampling date, abortion history in the farm) were recorded when available. Collected samples of each farm were labeled accordingly with specific code to differentiate animals and farms.

In each farm, the selected pigs were restrained and blood was collected from the jugular vein into a sterile vacutainer plain tube. In the field, the tube was set tilted in the cooler box over night at room temperature to allow clotting and, 24 hours after, sera were harvested in microcentrifuge tube and keept at $4^{\circ} \mathrm{C}$ in the refrigerator. Once at the Central Veterinary Laboratory, sera were centrifuged at $3000 \mathrm{~g}$ for $5 \mathrm{~min}$ transferred into new micro centrifuge tubes and then frozen at $-20^{\circ} \mathrm{C}$ until use.

\subsection{Laboratory analyses \\ 2.4.1 Rose Bengal Test}

The Rose Bengale Test (RBT) was used as recommended ${ }^{[24]}$. Briefly, a volume of $30 \mu$ l of serum was mixed with an equal volume of antigen onto a slide. The slide was then shaken for $5 \mathrm{~min}$. The degree of agglutination was appreciated to interpret the result. Samples were classified as positive if any agglutination was observed and negative in the absence of agglutination.

\subsubsection{ELISA test}

All the sera were also screened using commercial kit developed by IDVet Screen ${ }^{\circledR}$ (IDVet Innovative, Diagnostics, France) for the detection of antibodies against Brucella based on the purified Brucella LPS antigen according to the manufacturer's instructions.

\subsubsection{Data analysis}

All collected data in the field were recorded into Microsoft Excel spreadsheet 2011 including the serological test results that were obtained. Thereafter all the results were exported to Epi-info software version 7.2 (Centre for Disease Control, USA, Atlanta) for more analyses. The relationship between variables with positive serological test results was analyzed with Chi-square. A test value was considered as statistically significant when $P$ value was less than 0.05 .

\section{Results}

A total of 814 samples were collected in both provinces. In both provinces, the cumulative IgG seroprevalence against specific antibodies of $B$. suis was $4.42 \%$ [95\% IC (3.16 6.13)] and 3.19\% [95\% IC (2.14 - 4.71)] when ELISA and RBT were used, respectively. No significant difference was found in the prevalence using both techniques $(p>0.05)$. At the province level, 3.53\% [95\% (2.07-5.90)] of pigs were found with antibodies against $B$. suis in Kinshasa and 5.38\% [95\% IC (3.15- 8.24)] in Kongo Central when ELISA was used. No significant difference was found between both provinces using ELISA technique (RR: $0.6570 p=0.26 ; \chi 2$ $=1.23$ ). Similarly, no significant difference was found ( $p=0.41 ; \chi 2=0.66$ ) when RBT was used in samples collected in Kinshasa (2.59\%) [95\% IC (1.37-4.73)] and Kongo Central (3.85\%) [95\% IC (2.25 - 6.40)] as shown in Table 1.

In both provinces, the IgG seroprevalence against specific antibodies of $B$. suis was not statistically different $(p=0.199)$ in pigs group between 7 and 12 months (3.53\% [95\% IC 2.105.59]) compared to pig group age $>12$ months (5.54\% [95\% IC (3.50-8.57]). When RBT was used, not statistically different $(\mathrm{p}=0.85)$ was obtained in pigs group between 7 and 9 months (3.09\% [95\% IC 1.77-5.26]) compared to pig group age $>12$ months (3.32\% [95\% IC 1.81-5.89]).

When both sex were compared, significantly higher prevalence $(p=0.0028 ; \chi 2=8.9)$ was obtained in males $(8.6 \%$, 95\% IC (4.76-12.59) compared to females (3.15\%, 95\% IC (1.96-4.97) using ELISA. Similarly, a significant difference ( $p=0.001 ; \chi 2=16.04)$ was found between males $(5.68 \%, 95 \%$ (2.97-9.72) compared to females (2.32\%, 95\% IC (1.33-3.96) using RBT. Similarly, significantly higher prevalence was recorded indigenous breed pigs $(15.18 \%$, 95\% IC (9.1023.19)) compared to improved breeds $(2.7 \%$, 95\% IC (1.684.27) using ELISA ( $p=0.001 ; \chi 2=32.65)$. A significant high prevalence was also recorded in indigenous breed $(9.82 \%$, 95\% IC (5.01-16.89)) compared to improved ones $(2.1 \%$, $95 \%$ IC (1.25-3.58) when RBT was used $(p=0.001 ; \chi 2$ $=16.04)$.

At farm system level, the IgG seroprevalence against specific antibodies for B. suis of 3.62\% [95\% IC (2.34 - 5.52)] and $6.76 \%$ [95\% IC (3.75 - 11.09)] was detected in animals rearing in confinement compared to divagation, respectively using ELISA. No significant difference was obtained, ( $p=0.058 ; \chi 2=3.59)$. Similarly, no significant difference was obtained when RBT was used $(p=0.52 ; \chi 2=0,040)$ in pigs reared in confinement $(2.97 \%$, 95\% IC (1.82 - 4.74) compared to those in divagation (3.86\%, 95\% IC (1.68 7.47).

Table 1: Seroprevalence of swine brucellosis in Kinshasa and Kongo Central provinces in the Democratic Republic of the Congo using ELISA and RBT tests

\begin{tabular}{|c|c|c|c|c|c|c|c|c|c|c|c|}
\hline \multirow[b]{2}{*}{ Province } & \multirow[b]{2}{*}{ Tested sample } & \multicolumn{5}{|c|}{ IgG ELISA } & \multicolumn{5}{|c|}{ RBT } \\
\hline & & Positive samples & Prevalence (\%) & $95 \%$ IC & $P$ value & $X^{2}$ & $\mid \begin{array}{l}\text { Positive } \\
\text { samples }\end{array}$ & Prevalence (\%) & $95 \%$ IC & $P$ value & $X^{2}$ \\
\hline Kinshasa & 424 & 15 & 3.53 & $2.07-5.90$ & 026 & 123 & 11 & 2.59 & $1.37-4.73$ & (4) & 0,06 \\
\hline Kongo Central & 390 & 21 & 5.38 & $3.15-8.24$ & 0.20 & $\mid$ & 15 & 3.85 & $2.25-6.40$ & 0.41 & 0.00 \\
\hline Total & 814 & 36 & 4.42 & $3.16-6.13$ & & & 26 & 3.19 & $2.14-4.71$ & & \\
\hline
\end{tabular}


Table 2: IgG seroprevalence of swine brucellosis by sex, age, race and breeding system in Kinshasa and Kongo Central provinces using ELISA and RBT test

\begin{tabular}{|c|c|c|c|c|c|c|c|c|c|c|c|}
\hline & & \multicolumn{5}{|c|}{ ELISA } & \multicolumn{5}{|c|}{ RBT } \\
\hline Variable & $\begin{array}{c}\text { Tested } \\
\text { samples }\end{array}$ & $\begin{array}{l}\text { Positive } \\
\text { samples }\end{array}$ & $\begin{array}{c}\text { Prevalence } \\
(\%)\end{array}$ & $95 \%$ IC & $\begin{array}{c}P \\
\text { value }\end{array}$ & $X^{2}$ & $\begin{array}{l}\text { Positive } \\
\text { samples }\end{array}$ & $\begin{array}{c}\text { Prevalence } \\
(\%)\end{array}$ & $95 \%$ IC & \begin{tabular}{|c|}
$\boldsymbol{P}$ \\
value
\end{tabular} & $X^{2}$ \\
\hline \multicolumn{12}{|c|}{ Sex } \\
\hline $\mathrm{F}$ & 603 & 19 & 3.15 & $1.96-4.97 \mathrm{~b}$ & 0.0028 & 8.9 & 14 & 2.32 & $1.33-3.96 \mathrm{~b}$ & 0.017 & 5.72 \\
\hline$M$ & 211 & 17 & 8.6 & $4.76-12.59 a$ & & & 12 & 5.68 & $2.97-9.72 \mathrm{a}$ & & \\
\hline \multicolumn{12}{|c|}{ Age (months) } \\
\hline $07-12$ & 453 & 16 & 3.53 & $2.10-5.79$ & 0.166 & 1.91 & 14 & 3.09 & $1.77-5.26$ & 0.85 & 0.04 \\
\hline$>12$ & 361 & 20 & 5.54 & $3.50-8.57$ & & & 12 & 3.32 & $1.81-5.89$ & & \\
\hline \multicolumn{12}{|c|}{ Race } \\
\hline Indigenous & 112 & 17 & 15.18 & 9.10-23.19 & 0.001 & 32.65 & 11 & 9.82 & $5.01-16.89$ & 0.001 & 16.04 \\
\hline Improuved breeds & 702 & 19 & 2.7 & \begin{tabular}{|l|}
$1.68-4.27$ \\
\end{tabular} & & & 15 & 2.1 & $1.25-3.58$ & & \\
\hline \multicolumn{12}{|c|}{ Farm System } \\
\hline Confinement & 607 & 22 & 3.62 & $2.34-5.52$ & 0.04 & 3.59 & 18 & 2.97 & $1.82-4.74$ & 0.52 & 0.40 \\
\hline Divagation & 207 & 14 & 6.76 & $3.75-11.09$ & & & 8 & 3.86 & $1.68-7.47$ & & \\
\hline
\end{tabular}

\section{Discussion}

This study was designed to determine the seroprevalence of brucellosis in Kinshasa and Kongo Central provinces in pigs showing no apparent signs of diseases reared in confinement or divagation breeding system. Increased awareness of animal brucellosis in sub-Saharan Africa and a rapid spread of the disease have been reported ${ }^{[25]}$. Brucella suis epidemiology is important not only for the pig industry but also it constitutes a real threat for other swine production systems such as the familial farming in peri-urban and rural areas in different African countries. Since the bacterium can spread easily from swine to other species, the infections related to different $B$. suis biovars have also been reported elsewhere in non-natural host animals, such as horses [26], dogs [27] and cattle [28]. Mainwhile, $B$. suis has also been reported in wild pigs elsewhere ${ }^{[29,30,31]}$.

In the context of this study area where the survey was carried out, the animals were kept in a rambling system in certain areas and also in a confinement system with a letting go. This constitutes a risk factor for contamination of animals. Indeed, the result obtained in this study showed that antibodies specific for $B$. suis were detected in all the pig production systems practiced in the two provinces sampled although no significant difference was recorded as far as the farming system was concerned.

Using both test, higher seroprevalence was recorded in pigs more than 1 year of age compared to young animal (7-12 months). This finding was in agreement with that observed by others researchers ${ }^{[32,33]}$. This higher seroprevalence among adult might be related to sexual maturity and advancing age of animals ${ }^{[34]}$. Nevertheless, results obtained in this study do not corroborate with these reported by researcher ${ }^{[35]}$ where higher seroprevalence was recorded in young animal compared to adult. These animals may be highly exposed to the risk of infection through consumption of feed contaminated or others materials contaminants (lochial secretion, sperm, urine...) from infected pigs ${ }^{[36]}$. It was also confirmed that primary bacteremia can persist up-to 3 months and infected pigs remain permanently infected ${ }^{[37]}$. However, it was demonstrated that age is no determinant factor of susceptibility for pig brucellosis ${ }^{[38]}$.

Based on sex, higher prevalence was recorded in male compared to female as reported ${ }^{[39]}$. This finding is in contrast with study conduct elsewhere ${ }^{[38,40]}$ where higher prevalence of porcine brucellosis was reported in males than females. However, Brucella antibody titers are not associated with sex [41], both males and females have equal chance of getting infection due to free ranging systems (uncontrolled coupling) and exchange of male between farmers in confinement system. IgG Seroprevalence obtained in this study using ELISA in both sampled provinces shown an higher proportion of seropositivity compared to that reported in other areas; $0.6 \%$ in Nigeria ${ }^{[42]}, 0.18 \%$ in Uganda ${ }^{[43]}, 3 \%$ in Greece in intensively managed swine herds ${ }^{[44]}, 3.9 \%$ in Nepal ${ }^{[33]}$. It has reported by researcher that the prevalence and severity of disease may vary with the breed (indigenous vs imported), sex, age, geographic location, management system (free range system and confinement), type of diagnostic test used and environmental factor (temperature and humidity). Thus environmental factors play in important role for bacteria persistence and growth as well as the biovar of the organism [45, 46, 47].

RBT was lower than $4.5 \%$ obtained in Ethiopia from slaughtered animals at the abattoir ${ }^{[35]}, 6.7 \%$ in Bangladesh ${ }^{[34]}$ and $30.6 \%$ in Nigeria ${ }^{[39]}$. Study conducted elsewhere shown that RBT has high sensitivity (100\%) but less specificity (84\%) for brucella diagnosis ${ }^{[48,49]}$. That means all positives results required to be confirmed by other more specific test such as ELISA while negative result of RBT allowed in some high degree to exclude active brucellosis such as early stages of incubation or immediate after abortion ${ }^{[50,51]}$.

These results reveal that brucellosis is a widespread problem among swine populations raised in divagation and confinement in sampled provinces of DRC. In Contrast, a previous study conduct elsewhere showed that pig brucellosis should not be considered as widespread problem among pig populations raised in intensive rearing conditions or on large farms with semi-intensive rearing system ${ }^{\text {[22, 53]. }}$.

\section{Conclusion}

The results of the present study confirmed $B$. suis infection in pigs farms and zoonotic transmission to pig handlers. To our knowledge, this study reports the first investigation of $B$. suis in DRC particularly in Kinshasa and Kongo central provinces. For better understanding of Brucellosis epidemiology in the country, several studies need to be conducted in different host to determine the dynamic transmission of disease in livestock's.

\section{Conflict of interest}

The authors declare that they are no conflicts of interest.

\section{References}

1. Perry B, Sones K. Poverty reduction through animal health. Science. 2007; 315(5810):333-334.

2. Godfroid J, Scholz HC, Barbier T., Nicolas C., Wattiau P., Fretin D., Whatmore A.M., Cloeckaert A., et al. 
Brucellosis at the animal/ecosystem/human interface at the beginning of the 21st century. Preventive Veterinary Medicine. 2011; (102):118-131.

3. McDermott J, Grace D, Zinsstag J. Economics of brucellosis impact and control in low-income countries. Revue scientifique et technique, Office International des Epizooties. 2002; 32(1):249-261.

4. Godfroid J, Brucellosis in wildlife. Revue Scientifique et Technique. 2002; 21:277-286.

5. Seleem MN, SM Boyle, N Sriranganathan. Brucellosis: A re-emerging zoonosis, Veterinary Microbiology. 2010; 140:392-398.

6. EFSA. Scientific Opinion of the Panel on Animal Health and Welfare (AHAW) on a request from the Commission on porcine brucellosis (Brucella suis). The EFSA Journal. 2009; 7(6):1144:1-112.

7. Achap P, Szyfres B. Zoonoses et maladies transmissibles à l'homme et aux animaux. Office International des Epizooties: Paris, 2005, 693.

8. Cventnic Z, Toncic J, Spicic J, Lojkic M, Terzic S et al. Brucellosis in wild boar (Sus scrofa) in the Republic of Croatia. Veterinary Medicine Czech. 2004; 49:115-122.

9. Swai ES, Schoonman L. A survey of zoonotic diseases in trade cattle slaughtered at Tanga city abattoir: A cause of public health concern. Asian Pacific Journal of Tropical Biomedicine. 2012; 2(1):55-60.

10. Cortina ME, Balzano RE, Rey Serantes DA, Caillava AJ, Elena S, Ferreira AC et al. A bacterial glycoengineered antigen for improved serodiagnosis of porcine brucellosis. Journal of Clinical Microbiology. 2016; 54:1448-1455.

11. Ducrotoy Marie J, Wilson J Bertu, Reuben A Ocholi, Amahyel M Gusi, Ward Bryssinckx, Sue Welburn et al. Brucellosis as an Emerging Threat in Developing Economies: Lessons From Nigeria, PLoS Negl Trop Dis. 2014; 24:8(7):e3008.

12. Di Febo T, Luciani M, Portanti O, Bonfini B, Lelli R, Tittarelli $\mathrm{M}$ et al. Development and evaluation of diagnostic tests for the serological diagnosis of brucellosis in swine. Veterinary Italian. 2012; 48:133156.

13. Praud A, Gimenez O, Zanella G, Dufour B, Pozzi N, Antras $\mathrm{V}$ et al. Estimation of sensitivity and specificity of five serological tests for the diagnosis of porcine brucellosis. Preventive Veterinary Medicine. 2012; 104:94-100.

14. Redkar R, Rose S, Bricker B, Del Vecchio V. Real-time detection of Brucella abortus, Brucella melitensis and Brucella suis. Molecularand Cellular Probes. 2001; 15:43-52.

15. Garcia-Yoldi D, Marin CM, De Miguel MJ, Munoz PM, Vizmanos JL, Lopez-Goni I et al. Multiplex PCR assay for the identification and differentiation of all Brucella species and the vaccine strains Brucella abortus S19 and RB51 and Brucella melitensis Rev1. Clinical Chemistry. 2006; 52:779-781.

16. Hänsel C, MertensK, Elschner MC, Melzer F. Novel realtime PCR detection assay for Brucella suis. Veterinary Record Open. 2005; 2:e000084.

17. Foster JT, Okinaka RT, Svensson R, Shaw K, De BK, Robison RA et al. Real-time PCR assays of singlenucleotide polymorphisms defining the major Brucella clades. Journal of Clinical Microbiology. 2008; 46:296301.
18. Whatmore AM, Murphy TJ, Shankster S, Young E, Cutler SJ, Macmillan AP et al. Use of amplified fragment length polymorphism to identify and type Brucella isolates of medical and veterinary interest. J Clin Microbiol. 2005; 43:761-769.

19. Eshitera EE, Githigia SM, Kitala P, Thomas LF, Fevre EM, Harrison LJ et al. Prevalence of porcine cysticercosis and associated risk factors in Homa Bay District, Kenya. BMC Veterinary Research. 2012; 8:234.

20. Godfroid J, AL Dahouk S, Pappase G, Rothf F, Matopeg G, Mumah J et al. A "One Health" surveillance and control of brucellosis in developing countries: moving away from improvisation. Comp. Immunol. Microbiol. Infect. Dis. 2013; 36:241-248.

21. Ducrotoy M, WJ Bertu, G Matope, S Cadmus, R Conde, Álvarez AM et al. Moriyón. Brucellosis in Sub-Saharan Africa: Current challenges for management, diagnosis and control, Acta Tropica. 2017; 165:179-193.

22. Bula M, Ndumbi MW, Banza M. Dépistage de la brucellose Bovine dans le sud Est du Zaïre par l'épreuve de fixation de complément. Revue Scientifique et Technique Office international Epizooties. 1987; 6(4):1037-1042.

23. Thrusfield MV. Veterinary Epidemology. 2nd edition. Blackwell Science, Oxford, 1995, 83.

24. Alton GG, Jones ML, Angus RD, Verger JM. In: Bacteriologic Methods and Serologic Methods. Techniques for the Brucellosis Laboratory. Institut National de la Recherche Agronomique, Paris, France, 1988, 13-62.

25. Pappas G. The changing Brucella ecology: novel reservoirs, new threats. International Journal of Antimicrobial Agents. 2010; 36:8-11.

26. Cvetnic Z, Spicic S, Curi S, Jukic B, Lojkic M, Albert $D$ et al. Isolation of Brucellasuisbiovar 3 from horses in Croatia. Veterinay Record. 2005; 156:584-585.

27. Ramamoorthy S, Woldemeskel M, Ligett A, Snider R, Cobb R, Rajeev S et al. Brucella suis infection in dogs, Georgia, USA. Emerging Infectious Disease. 2011; 12:2386-2387.

28. Fretin D, Mori M, Czaplicki G, Quinet C, Maquet B, Godfroid J et al. Saegerman C. Unexpected Brucella suis biovar 2 infection in a dairy cow, Belgium. Emerging Infectious Disease. 2013; 19:2053-2054.

29. Grégoire F, Mousset B, Hanrez D, Michaux C, Walravens $\mathrm{K}$, Linden A et al. A serological and bacteriological survey of brucellosis in wild boar (Sus scrofa) in Belgium, BMC Veterinary Research. 2012; 8:80.

30. Closa-Sebastià F, Casas-Díaz E, Cuenca R, Lavín S, Mentaberre G et al. Brucella species antibodies and isolation in wild boar in north-east Spain. Veterinary Record. 2010; 167:826-828.

31. Melzer F, Lohse R, Nieper H, Liebert M, Sachse K. A serological study on brucellosis in wild boars in Germany. European Journal of Wildlife Research. 2007; 53:153-157.

32. Poudel SR, Gupta R, Ratala DR. Sero-prevalence of brucellosis in pigs in 6 VDC's of Rupandehi District, Nepal. Nepalese Journal of Zoology, 2014, 42.

33. Sharma S, Doj Raj Khanal, Yuvraj Panth. SeroPrevalence of Brucellosis in Pigs of Bhaktapur, Kavre and Banke Districts of Nepal, International Journal of Applied. Science Biotechnology. 2017; 5(4):466-469. 
34. Rahman MS, Nuruzzaman M, Ahasan MS, Sarker RR, Chakrabartty A et al. Prevalence of brucellosis in pigs: the first report in Bangladesh. Bangledesh Journal Veterinary Medicine. 2012; 10:75-80.

35. Kebeta M.M, Mamo G, Kassa T, Assaye M, Ashenafi H, Zewdu E. Seroprevalence of Brucellosis from Pigs: The First Report in Central Ethiopia. J Veterinar Sci Technol. 2015; 6(2):215.

36. Kebede T, Ejeta G, Ameni G. Sero-prevalence of bovine brucellosis in smallholder farms in central Ethiopia (Wuchale-Jidadistrict). Revue de Médecine Véterinaire. 2008; 159:3-9.

37. Office International des Epizooties (OIE): Porcine Brucellosis. In: Manual of standards for diagnostic tests and vaccines, World Organisation for Animal Health, Paris, France, 2009.

38. Alton GG. Brucella suis. In Animal brucellosis, K. Nielsen \& J.R. Duncan, eds. CRC Press, Boca Raton, Florida, 1990, 411-422.

39. Ngbede EO, Momoh AH, Ruben Sylvester Bala RS, Madaki BD, Maurice NA. An Abattoir-Based Study on Serodiagnosis of Swine Brucellosis in Makurdi, Benue State, North-Central Nigeria. Journal of Advanced Veterinary Research. 2013; 3(2):57-59.

40. Hussein AAA, ASM Sayed, MA El Feki. Seroepidemiological study on human brucellosis in Assiut Governorate. Egypt. J. Immumol. 2005; 12:49-56.

41. Muma JB, Samui KL, Siamudaala VM, Oloya J, Matope G, Omer MK et al. Prevalence of antibodies to Brucella spp. and individual risk factors of infection in traditional cattle, goats and sheep reared in livestock-wildlife interface areas of Zambia. Tropical Animal Health and Production. 2006; 38:195-206.

42. Onunkwo JI, Njoga EO, Nwanta JA, Shoyinka SVO, Onyenwe IW, Eze JI et al. Serological Survey of Porcine Brucella Infection in South East, Nigeria. Nigerian Veterinary Journal. 2011; 32(1):60-62.

43. Erume J, Kristina Roesel, Michel M. Dione, Francis Ejobi, Gerald Mboowa, Joseph M. Kungu, Joyce Akol, Danilo Pezo, Hosny El-Adawy, Falk Melzer, et al. Serological and molecular investigation for brucellosis in swine in selected districts of Uganda, Trop Anim Health Prod. 2016; 48:1147-1155.

44. Burriel AR, Varoudis L, Alexopoulos C, Kritas S, Kyriakis SC. Serological evidence of Brucella species and Leptospira interrogans serovars in Greek swine herds. Journal of Swine Health and Production. 2003; 11:186-189.

45. Ghani M, Zeb A, Siraj M, Naeem M. Sero-incidence of bovine brucellosis in Peshawar district of Pakistan. Indian Journal of Animal Science. 1998; 68(5):457.

46. Uddin JM, Rahman MS, Hossain MA, Akter SH, Majumder S, Park JH et al. Relation between Brucellosis and husbandry practices in goats in Bangladesh. Korean Journal of Veterinary Service. 2007a; 30:259-267.

47. Uddin JM, Rahman MS, Akter SH, Hossain MA, Islam MT, Islam MA et al. Seroprevalence of Brucellosis in small ruminants in selected area of Bangladesh. Korean Journal of Veterinary Service. 2007; 30:511-525.

48. Akhtar R, Chaudhry ZI, Shakoori AR, Ahmad M, Aslam A. Comparative efficacy of conventional diagnostic methods and evaluation of polymerase chain reaction for the diagnosis of bovine brucellosis. Vet. World. 2010; 3:53-56.

49. Barroso GP, Rodriguez CPR, Extremera BG, Maldonado MA, Huertas GG, Salguero MA et al. Study of 1,595 brucellosis cases in the Almeria province (1972-1998) based on epidemiological data from disease reporting. Rev. Clin. Espanola. 2002; 202:577-582.

50. Swai ES, Schoonman L. The Use of Rose Bengal Plate Test to Asses Cattle Exposure to Brucella Infection in Traditional and Smallholder Dairy Production Systems of Tanga Region of Tanzania. Veterinary Medicine International. 2010; 2:1-8. Article ID 837950.

51. Gul ST, Khan A. Epidemiology and epizootology of brucellosis. A review. Pak. Vet. J. 2007; 27:145-151.

52. Spicic S, Zdelar-Tuk M, Racic I, Duvnjak S, Cvetnić Z. Serological, bacteriological and molecular diagnosis of brucellosis in domestic animals in Croatia. Croatia Medicine Journal. 2010; 51(4): 320-6.

53. Spicic S, Zdelar-Tuk M, Racic I et al. Sensitivity of actual laboratory diagnostic methods used for surveillance of swine brucellosis in Croatia. International Journal Applied Research Veterinary Medicine. 2013: 11(3):167-73.

\section{Author's Details:-}

\section{Tshilenge Mbuyi Georges}

a) Central Veterinary Laboratory, Wangata Street, Gombe, P.O. Box 8842, Kinshasa, Democratic Republic of the Congo

b) Faculty of Veterinary Medicine, University of Kinshasa, University Street, P.O. Box 117, Kinshasa XI, Democratic Republic of the Congo

c) Center of Documentation and Research on Zoonotic Diseases, Chaussé Kimwenza, P.O. Box 774, Kinshasa XI, Democratic Republic of the Congo

\section{Kazadi Kawaya E}

Faculty of Veterinary Medicine, University of Kinshasa, University Street, P.O. Box 117, Kinshasa XI, Democratic Republic of the Congo

\section{Bha Nsekene G}

Faculty of Veterinary Medicine, University of Kinshasa, University Street, P.O. Box 117, Kinshasa XI, Democratic Republic of the Congo

\section{Katshongo Mushindua Freddy}

a) Center of Documentation and Research on Zoonotic Diseases, Chaussé Kimwenza, P.O. Box 774, Kinshasa XI, Democratic Republic of the Congo

b) High Institute Medical Technic of Kinshasa, Chaussée Kimwenza, P.O. Box 774, Kinshasa XI, Democratic Republic of the Congo

\section{Balowa Katshayi Louison}

Central Veterinary Laboratory, Wangata Street, Gombe, P.O. Box 8842, Kinshasa, Democratic Republic of the Congo

\section{Tshinguta londji charlotte}

Central Veterinary Laboratory, Wangata Street, Gombe, P.O. Box 8842, Kinshasa, Democratic Republic of the Congo

\section{Dibungi Luseba Jean Marie}

Faculty of Veterinary Medicine, University of Kinshasa, University Street, P.O. Box 117, Kinshasa XI, Democratic Republic of the Congo 


\section{Kandu-lelo Clement}

Faculty of Veterinary Medicine, University of Kinshasa, University Street, P.O. Box 117, Kinshasa XI, Democratic Republic of the Congo

\section{Lufulwabu Kasuyi Jean}

a) Center of Documentation and Research on Zoonotic Diseases, Chaussé Kimwenza, P.O. Box 774, Kinshasa XI, Democratic Republic of the Congo

b) High Institute Medical Technic of Kinshasa, Chaussée Kimwenza, P.O. Box 774, Kinshasa XI, Democratic Republic of the Congo

\section{Mpiana Tshipamba Serge}

Central Veterinary Laboratory, Wangata Street, Gombe, P.O. Box 8842, Kinshasa, Democratic Republic of the Congo

\section{Masumu Justin}

a) Central Veterinary Laboratory, Wangata Street, Gombe, P.O. Box 8842, Kinshasa, Democratic Republic of the Congo

b) Faculty of Veterinary Medicine, National Pedagogic University, Matadi/Liberation Street, P.O. Box 8815, Kinshasa, Democratic Republic of the Congo

c) National Institute for Biomedical Research (INRB), 5345 Huileries Street, P.O. Box 1197, Kinshasa, Democratic Republic of the Congo

d) Interdisciplinary Centre for Health Risk Management (CIGERS), P.O. Box 215 Kin 1, Kinshasa, Democratic Republic of the Congo 